\title{
Periodontal Conditions and Whole Salivary IL-17A and -23 Levels among Young Adult Cannabis sativa (Marijuana)-Smokers, Heavy Cigarette-Smokers and Non-Smokers
}

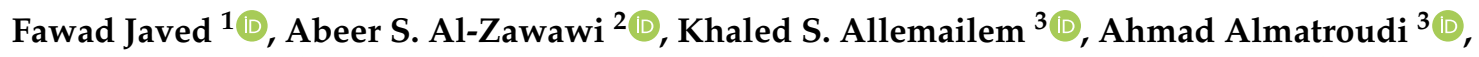 \\ Abid Mehmood ${ }^{4}{ }^{(\mathbb{D}}$, Darshan Devang Divakar ${ }^{5}{ }^{-}$and Abdulaziz A. Al-Kheraif ${ }^{5, *}$ \\ 1 Department of Orthodontics and Dentofacial Orthopedics, Eastman Institute for Oral Health, \\ University of Rochester, Rochester, NY 14620, USA; fawjav@gmail.com \\ 2 Department of Periodontics and Community Dentistry, King Saud University, Riyadh 60169, Saudi Arabia; \\ a.s.alzawawi1@gmail.com \\ 3 Department of Medical Laboratories, College of Applied Medical Sciences, Qassim University, \\ Buraydah 51452, Saudi Arabia; k.allemailem@qu.edu.sa (K.S.A.); aamtrody@qu.edu.sa (A.A.) \\ 4 Department of Dentistry, Postgraduate Medical Center, Karachi 75500, Pakistan; \\ drabidmehmood12@gmail.com \\ 5 Dental Biomaterials Research Chair, Dental Health Department, College of Applied Medical Sciences, \\ King Saud University, P.O. Box 10219, Riyadh 11433, Saudi Arabia; darshandevang@gmail.com \\ * Correspondence: aalkhuraif@ksu.edu.sa; Tel.: +966-5025-1250; Fax: +966-0541-1222
}

Received: 12 August 2020; Accepted: 9 October 2020; Published: 13 October 2020

Abstract: In the United States, prevalence of marijuana-use has doubled in the past 2 decades. The aim was to compare the periodontal conditions and whole-salivary IL-17A and IL-23 levels among young adult marijuana-smokers, heavy cigarette-smokers and non-smokers. Self-reported marijuana-smokers, heavy-cigarette-smokers, non-smokers with periodontitis and periodontally-healthy non-smokers were included. Demographic data was recorded and full-mouth plaque index (PI), bleeding on probing (BoP), probing depth (PD) and clinical attachment loss (AL), marginal bone loss (MBL) and missing teeth were recorded. Levels of IL-17A and IL-23 levels were measured in the whole saliva. $p<0.01$ was considered statistically significant. Fifteen-marijuana-smokers, 15 heavy-cigarette-smokers, 16 non-smokers-with-periodontitis and 15 periodontally-healthy-non-smokers) were included. The clinicoradiographic parameters were worse among marijuana-smokers $(p<0.01)$, cigarette-smokers $(p<0.01)$ and non-smokers-with-periodontitis $(p<0.01)$ than periodontally-healthy-non-smokers. Marijuana- and cigarette-smokers had Stage-IV/Grade C and non-smokers with periodontitis had Stage-III/Grade-C. Salivary IL-17A and IL-23 levels were higher in marijuana-smokers than cigarette-smokers $(p<0.01)$ and non-smokers-with-periodontitis $(p<0.01)$. Whole salivary IL-17A and IL-23 levels were higher among cigarette-smokers than non-smokers with periodontitis $(p<0.01)$ and periodontally-healthy-individuals $(p<0.01)$. Marijuana- and heavy cigarette-smokers have comparable clinicoradiographic periodontal statuses. This rejects hypothesis-1. However, whole salivary immunoinflammatory response may be moderately worse in marijuana-smokers compared with heavy cigarette-smokers and non-smoker with periodontitis thereby supporting hypothesis- 2 .

Keywords: alveolar bone loss; Cannabis sativa; cigarette smoking; marijuana; probing depth; whole saliva 


\section{Introduction}

Marijuana (Cannabis sativa), commonly known as bud, ganja, grass, pot and weed, is a grayish-green mix of dried flowers of Cannabis sativa; and is the most commonly used psychotropic drug in the United States after alcohol [1,2]. Tetrahydrocannabinol (THC), is the main chemical responsible for most of marijuana's psychological effects including heightened sensory perception, sense of relaxation, laughter and increased appetite [3,4]. Moreover, Cannabinoids are anti-inflammatory agents by decreasing anti-oxidative activities and production of destructive-inflammatory cytokines and enhancing the induction of apoptosis and T-regulatory cells [5,6]. According to Hasin et al. [7], the prevalence of marijuana-use in the United States has doubled in the past 2 decades. Marijuana-use is more prevalent among males than females [1,2]; and its habitual use is associated disorders including but not limited to psychosis, pulmonary disorders and dependence/addiction [8]. Its use is more prevalent among males than females [1,2]. From a periodontal perspective, clinical studies $[9,10]$ have shown that the mean number of sites per individual with a probing depth (PD) and clinical attachment loss (AL) of $\geq 4 \mathrm{~mm}$ are significantly higher among frequent marijuana-smokers compared with individuals not using recreational drugs.

The inflammatory immune response plays a role in the progression and etiopathogenesis of periodontitis [11-13]. Under periodontal inflammatory diseases, such as periodontitis, proinflammatory cytokines enhance soft tissue inflammation and marginal bone loss (MBL) [14,15]. Activation of Th17 cells produces interleukin (IL)-17A, a proinflammatory cytokine that induces inflammation and bone resorption by stimulating the release of matrix metalloproteinases and chemokines [16]. Moreover, other cytokines including interferon-gamma (IFN- $\gamma$ ), IL-1 $\beta$ and tumor necrosis factor-alpha (TNF- $\alpha$ ) act synergistically to influence the effects of IL-17A $[14,15,17]$. Another cytokine, IL-23 that is produced by dendritic cells and macrophages plays a dominant role in IL-17A production [18]. It has been reported that IL-23 is associated with autoimmune destruction in diseases including allergic encephalomyelitis, arthritis and periodontitis [18-20]. In general, there is a clear consensus that expression of IL-17A and IL-23 in oral fluids (UWS and gingival crevicular fluid [GCF]) is associated with the etiopathogenesis of periodontitis [15,19-21]. Severity of periodontitis is worse in marijuana-smokers and individuals with a significantly higher daily frequency of smoking cigarettes compared with light-smokers (individuals smoking $<10$ cigarettes daily) $[9,10,22]$.

Hypothesis 1. Periodontal inflammatory parameters are worse among young adult marijuana-smokers and heavy cigarette-smokers compared with non-smokers with and without periodontitis.

Hypothesis 2. Whole salivary immunoinflammatory response is worse among young adult marijuana-smokers and heavy cigarette-smokers compared with non-smokers with and without periodontitis.

The aim was to compare the periodontal conditions and whole salivary IL-17A and IL-23 levels among young adult marijuana-smokers, heavy cigarette-smokers and non-smokers.

\section{Materials and Methods}

\subsection{Ethical Approval}

This study was approved by the human subject's ethics board of Postgraduate Medical Center, Karachi, Pakistan (Approval \# OS/DD/0157); and was conducted in accordance with the Helsinki declaration of 1975, as revised in 2013. All participants were aware that participation is completely voluntary and that withdrawal at any stage of the investigation bears no consequences. It was mandatory of individuals to have read and signed a written informed consent form. All participants were given verbal and written information about the significance of oral hygiene maintenance and deleterious effects of smoking on overall health. Moreover, all participants were also provided written 
information and contact details about "a tobacco/narcotic cessation program" that could help them quit the habit.

\subsection{Inclusion and Exclusion Criteria}

Self-reported heavy smokers (individuals who had at least 40 pack-years of smoking) [23,24]; marijuana-smokers (individuals who were daily smoking marijuana for at least 1 year) [25]; and non-smokers (individuals that reported to have never used any form of tobacco-product and/or recreational drug) were included $[13,26]$. Self-reported dual-smokers (individuals smoking cigarettes as well as marijuana), light and moderate smokers, patients with systemic diseases such as HIV+ individuals and patients with cardiovascular, hepatic, endocrine and/or renal diseases were excluded. Pregnant/lactating females, edentulous individuals and bilateral maxillary and mandibular third molars were not assessed. Moreover, patient that reported to have undergone periodontal treatment (such as ultrasonic scaling, scaling and root planing and/or guided bone or tissue regeneration procedures) and had used probiotics, antibiotics, steroids, cancer therapy and/or non-steroidal anti-inflammatory medications were excluded.

\subsection{Questionnaire}

Data related to age, gender, duration of cigarette-smoking (in pack-years) and marijuana smoking (in years) and mode of marijuana smoking (joint, spliff, and/or pot) was recorded. Participants were also asked about their highest level of education (school-, college- and university-level) they had attained. Individuals that had attained education from the Pakistani education system up to Grade-10 were categorized as having "school-level education" [27,28]. Individuals that had attained an additional of 2-years of education after graduation from school were categorized as having "college-level education" [28]. Individuals with University level education were defined as individuals who had graduated from a university [29]. Reason for smoking cigarettes and marijuana and family history of cigarette and marijuana smoking were also asked for. Patients were inquired if they had any interest and/or intention of quitting cigarette and marijuana smoking.

\subsection{Clinicoradiographic Periodontal Parameters}

In all patients full-mouth clinical AL [30], bleeding on probing (BOP) [31], PD [32] and plaque index (PI) [31] were measured by a skilled and standardized examiner (Kappa 0.85). These measurements were performed on 6 surfaces per tooth (midlingual/palatal, distolingual/palatal, mesiolingual/palatal, distobuccal, midbuccal and mesiobuccal). Number of missing teeth were recorded in all groups. Grossly-carious teeth with root remnants embedded in the jaw-bone were also considered missing. Using the long-cone paralleling-technique [33,34] digital intra-oral radiographs (Intra oral X-Ray-Systems-NOMAD/Pro-2 Gendex-Hatfield, PA, USA) were taken for all teeth. In all radiographs, marginal-bone-loss (MBL) was demarcated as the vertical void from 2-mm under the cement-enamel interface to the crest of interdental bone [35]. Radiographic assessments were performed by an experienced researcher (Kappa score 0.93) who was blinded to the study groups.

\subsection{Periodontal Health and Staging and Grading of Periodontitis}

Periodontal health was defined as a state of absence of the symptoms and signs of periodontal disease [36]; and periodontitis was defined using the following parameters: clinical AL of at least 1-2 $\mathrm{mm}, \mathrm{PD}$ of $\geq 4 \mathrm{~mm}$ and horizontal MBL as described elsewhere [37].

\subsection{Collection of Unstimulated Whole Saliva Samples and Determination of Whole Salivary IL-17A and IL-23 Levels}

The UWS samples were collected by a calibrated researcher (Kappa 0.9) as described in previous studies [38,39]. In summary, all UWS samples were collected during early morning hours (between 7:00 a.m. and 8:00 a.m.) with the patients being in a fasting state. Patients were comfortably seated on a 
chair in a quiet room and requested to allow UWS to accumulate in the oral cavity over a 5-min duration. During this time, patients were advised to refrain from deglutition and jaw/lip movements. Patients were them requested to expectorate the UWS into a disposable plastic funnel, which was coupled with a gauged measuring-cylinder. The amount of expectorated UWS was recorded in milliliters. For each individual per group, unstimulated whole salivary flow rate (SFR) was determined in milliliters per minute ( $\mathrm{mL} / \mathrm{min})$. The UWS samples were transferred to sterile plastic tubes with lid ("Fisherbrand ${ }^{\mathrm{TM}}$ Premium Microcentrifuge Tubes, Waltham, MA, USA) and centrifuged in a cold room at $3000 \mathrm{rpm}$ for $5 \mathrm{~min}$. The supernatant was collected and stored at $-80^{\circ}$ Celsius. All UWS samples were assessed for IL-17A and IL-23 levels within $24 \mathrm{~h}$ of collection.

\subsection{Assessment of Whole Salivary IL-17A and -23 Levels}

The IL-17A and IL-23 levels were assessed using a technique based on flow-cytometry (Luminex $x$-MAP technique, Luminex, Austin, TX, USA) as described in the study by Liukkonen et al. [15]. The supernatant was thawed and IL-17A and IL-23 levels were determined using standard kits (MILLIPLEX-map-kit, Human cytokine/chemokine panel, Millipore, Billerica, MA, USA) according to the guidelines provided by the manufacturer ${ }^{++}$. Whole salivary IL-23 and IL-17A concentrations were recorded in picograms per milliliter $(\mathrm{pg} / \mathrm{mL})$. The detection limits of IL-23 and IL-17A were $28.6 \mathrm{pg} / \mathrm{mL}$ and $0.2 \mathrm{pg} / \mathrm{mL}$, respectively. The detection limits of IL-23 and IL-17A were $28.6 \mathrm{pg} / \mathrm{mL}$ and $0.2 \mathrm{pg} / \mathrm{mL}$, respectively. Laboratory-based investigations were performed by a trained investigator (Kappa 0.91) who was blinded to the study groups.

\subsection{Statistical Analysis}

A computer-based statistical software (SPSS. Version 20, Chicago, IL, USA) was used to perform group comparisons in relation to clinicoradiographic parameters, SFR and whole salivary IL-17A and -23 levels. The Kolmogorov-Smirnov test was used to assess data normality. Group-wise, statistical evaluations were done using one-way-analysis-of variance and Bonferroni post-hoc adjustment tests. A $p$-value, which was less than 0.01 was designated as an indicator of statistical significance.

\section{Results}

\subsection{General Characteristics of the Study Groups}

In total, 15 marijuana-smokers, 15 heavy cigarette-smokers, 16 non-smokers with periodontitis and 15 periodontally-health non-smokers were included. All participants were male with no statistically significant difference in age. Marijuana-smokers were smoking marijuana as a "spliff" $10.6 \pm 0.4$ times daily for the past $11.1 \pm 0.4$ years. Cigarette-smoking had a smoking history of $43.6 \pm 1.05$ pack-years ( $36.5 \pm 5.2$ cigarettes per day). Graduate-level education was attained by $18.7 \%$ and $75 \%$ non-smokers with and without periodontitis, respectively. School-level education was the highest educational standard reported by $80 \%$ and $60 \%$ marijuana-smokers and heavy cigarette-smokers, respectively. Among cigarette-smokers, $73.3 \%$ and $26.7 \%$ individuals reported that they smoked cigarettes as the habit helped them manage psychological stress and concentrate, respectively. All marijuana-smokers reported that they used Cannabis to alleviate psychological stress. Tooth-brushing twice daily and flossing at least once daily was more often reported by non-smokers with a healthy periodontal status as compared to individuals in other groups (Table 1).

\subsection{Clinicoradiographic Status and Staging/Grading of Periodontitis}

The percentages of sites that presented with plaque accumulation, BoP, clinical AL and increased PD and MBL were significantly higher among marijuana-smokers $(p<0.01)$, cigarette-smokers $(p<0.01)$ and non-smokers with periodontitis $(p<0.01)$ compared with non-smokers without periodontitis. The numbers of missing teeth were significantly higher among marijuana-smokers $(p<0.01)$, cigarette-smokers $(p<0.01)$ and non-smokers with periodontitis $(p<0.01)$ compared with non-smokers 
without periodontitis. The numbers of missing teeth were higher among marijuana-smokers compared with non-smokers with periodontitis. Marijuana-smokers and cigarette-smokers had Stage IV/Grade C periodontitis and among non-smokers with periodontitis, the staging and grading of periodontitis was Stage III and Grade C, respectively (Table 2).

Table 1. Characteristics of the study cohort.

\begin{tabular}{|c|c|c|c|c|}
\hline Parameters & Marijuana-Smokers & Cigarette-Smokers & $\begin{array}{c}\text { Non-Smokers } \\
\text { with Periodontitis }\end{array}$ & $\begin{array}{l}\text { Periodontally-Healthy } \\
\text { Non-Smokers }\end{array}$ \\
\hline Number of Individuals $(n)$ & 15 & 15 & 16 & 15 \\
\hline Gender (male) & 15 & 15 & 16 & 15 \\
\hline $\begin{array}{c}\text { Age in Years }(\text { mean } \pm S D) \\
\text { Duration of }\end{array}$ & $38.3 \pm 0.5$ years & $40.2 \pm 0.5$ years & $38.4 \pm 0.7$ years & $40.3 \pm 0.4$ years \\
\hline $\begin{array}{l}\text { Marijuana-Smoking in } \\
\text { Years (mean } \pm \text { SD) }\end{array}$ & $11.1 \pm 0.4$ years & NA & NA & NA \\
\hline $\begin{array}{c}\text { Daily Frequency of } \\
\text { Marijuana-Smoking } \\
\text { (times/day) }\end{array}$ & $\begin{array}{c}10.6 \pm 0.4 \\
\text { times daily }\end{array}$ & NA & NA & NA \\
\hline $\begin{array}{c}\text { Duration of } \\
\text { Cigarette-Smoking in } \\
\text { Pack-years (mean } \pm \text { SD) }\end{array}$ & NA & $\begin{array}{l}43.6 \pm 1.05 \\
\text { pack years }\end{array}$ & NA & NA \\
\hline \multicolumn{5}{|l|}{ Education Status } \\
\hline School-level (n) (\%) & $12(80 \%)$ & $9(60 \%)$ & $6(37.5 \%)$ & 0 \\
\hline College-level (n) (\%) & $3(20 \%)$ & $6(40 \%)$ & $7(43.8 \%)$ & $3(25 \%)$ \\
\hline University-level $(n)(\%)$ & 0 & 0 & $3(18.7 \%)$ & $12(75 \%)$ \\
\hline \multicolumn{5}{|l|}{$\begin{array}{l}\text { Reasons for Marijuana or } \\
\text { Cigarette Smoking }\end{array}$} \\
\hline Stress-relief & $11(73.3 \%)$ & $15(100 \%)$ & NA & NA \\
\hline Helps with Concentration & $4(26.7 \%)$ & 0 & NA & NA \\
\hline No reason & 0 & 0 & NA & NA \\
\hline \multicolumn{5}{|l|}{$\begin{array}{l}\text { Most recent visit to } \\
\text { dentist/hygienist }\end{array}$} \\
\hline Within 6 months & 0 & 0 & 0 & 0 \\
\hline Within 6-12-months & 0 & 0 & 0 & $9(60 \%)$ \\
\hline Over 1-year ago & 0 & 0 & $3(18.7 \%)$ & $4(26.7 \%)$ \\
\hline Over 2-years ago & $1(6.7 \%)$ & $9(60 \%)$ & $9(56.3 \%)$ & $2(13.3 \%)$ \\
\hline Over 3 years ago & $2(13.3 \%)$ & $6(40 \%)$ & $2(12.5 \%)$ & 0 \\
\hline Don't remember & $12(80 \%)$ & 0 & $2(12.5 \%)$ & 0 \\
\hline \multicolumn{5}{|l|}{ Daily Toothbrushing } \\
\hline Once daily & $12(80 \%)$ & $9(60 \%)$ & $11(68.8 \%)$ & $13(86.7 \%)$ \\
\hline Twice daily & $3(20 \%)$ & $6(40 \%)$ & $5(31.2 \%)$ & $2(13.3 \%)$ \\
\hline Flossing at least once Daily & 0 & 0 & 0 & $5(33.3 \%)$ \\
\hline
\end{tabular}

NA: Not applicable. SD: Standard deviation.

Table 2. Clinicoradiographic parameters and staging/grading of periodontitis.

\begin{tabular}{|c|c|c|c|c|}
\hline Parameters (Mean \pm SD) & $\begin{array}{l}\text { Marijuana-Smokers } \\
\qquad(n=15)\end{array}$ & $\begin{array}{l}\text { Cigarette-Smokers } \\
\qquad(n=15)\end{array}$ & $\begin{array}{c}\text { Non-Smokers } \\
\text { with Periodontitis } \\
(n=16)\end{array}$ & $\begin{array}{l}\text { Periodontally-Healthy } \\
\text { Non-Smokers }(n=15)\end{array}$ \\
\hline Plaque Index & $69.3 \pm 8.2 \%$ & $63.4 \pm 6.2 \%$ & $60.5 \pm 9.1 \%$ & $10.3 \pm 6.4 \%$ * \\
\hline Bleeding on Probing & $30.5 \pm 4.8 \%^{+}$ & $27.3 \pm 5.1 \%^{\dagger}$ & $69.4 \pm 12.2 \%$ & $9.6 \pm 2.5 \%$ * \\
\hline Probing Depth & $7.1 \pm 0.3 \mathrm{~mm}$ & $6.8 \pm 0.2 \mathrm{~mm}$ & $4.5 \pm 0.3 \mathrm{~mm}$ & $0.6 \pm 0.08 \mathrm{~mm}^{*}$ \\
\hline Clinical Attachment Loss & $6.2 \pm 0.3 \mathrm{~mm}$ & $5.8 \pm 0.2 \mathrm{~mm}$ & $4.3 \pm 0.2 \mathrm{~mm}$ & $0.2 \pm 0.02 \mathrm{~mm}^{*}$ \\
\hline $\begin{array}{l}\text { Marginal Bone } \\
\text { Loss }^{(a)} \text { (mesial) }\end{array}$ & $7.2 \pm 0.5 \mathrm{~mm}$ & $6.2 \pm 0.4 \mathrm{~mm}$ & $4.9 \pm 0.3 \mathrm{~mm}$ & $0.2 \pm 0.05 \mathrm{~mm}^{*}$ \\
\hline $\begin{array}{l}\text { Marginal Bone } \\
\text { Loss }^{(a)} \text { (distal) }\end{array}$ & $7.4 \pm 0.3 \mathrm{~mm}$ & $6.08 \pm 0.6 \mathrm{~mm}$ & $5.1 \pm 0.4 \mathrm{~mm}$ & $0.2 \pm 0.06 \mathrm{~mm}^{*}$ \\
\hline Missing Teeth & $14.2 \pm 2.3$ teeth & $10.5 \pm 1.3$ teeth & $7.1 \pm 0.3$ teeth $\ddagger$ & $1.3 \pm 0.04$ teeth * \\
\hline Staging/Grading & Stage IV/Grade C & Stage IV/Grade C & Stage III/Grade C & NA \\
\hline
\end{tabular}

(a) Horizontal marginal bone loss extending to at least the mid-root length. NA: Not applicable. ${ }^{*}$ Compared with marijuana-smokers $(p<0.01)$, cigarette-smokers $(p<0.01)$ and non-smokers with periodontitis $(p<0.01) .{ }^{+}$Compared with non-smokers with- $(p<0.01)$ and without $(p<0.01)$ periodontitis. ${ }^{\ddagger}$ Compared with marijuana-smokers $(p<0.01)$. 


\subsection{Salivary Flow Rate and Whole Salivary IL-17A and IL-23 Levels}

There was no significant difference in the unstimulated whole SFR among marijuana-smokers, cigarette-smokers, non-smokers with periodontitis and periodontally-healthy non-smokers. Whole salivary IL-17A and IL-23 levels were significantly higher in marijuana-smokers compared with cigarette-smokers $(p<0.01)$ and non-smokers with periodontitis $(p<0.01)$. Whole salivary IL-17A and IL-23 levels were significantly higher among cigarette-smokers compared with non-smokers with periodontitis $(p<0.01)$ and periodontally-healthy individuals $(p<0.01)$ (Table 3$)$.

Table 3. Whole salivary flow rate and IL-17A and IL-23 levels.

\begin{tabular}{ccccc}
\hline Parameters & $\begin{array}{c}\text { Marijuana-Smokers } \\
(\boldsymbol{n}=\mathbf{1 5})(\mathbf{M e a n} \pm \text { SD) }\end{array}$ & $\begin{array}{c}\text { Cigarette-Smokers } \\
(\boldsymbol{n}=\mathbf{1 5}) \mathbf{( M e a n} \pm \text { SD) }\end{array}$ & $\begin{array}{c}\text { Non-Smokers with } \\
\text { Periodontitis }(\boldsymbol{n}=\mathbf{1 6}) \\
\text { (Mean } \pm \text { SD) }\end{array}$ & $\begin{array}{c}\text { Periodontally-Healthy } \\
\text { Non-Smokers }(\boldsymbol{n}=\mathbf{1 5}) \\
\text { (Mean } \pm \text { SD) }\end{array}$ \\
\hline SFR $(\mathrm{mL} / \mathrm{min})$ & $0.34 \pm 0.01 \mathrm{~mL} / \mathrm{min}^{*}$ & $0.33 \pm 0.01 \mathrm{~mL} / \mathrm{min}$ & $0.35 \pm 0.05 \mathrm{~mL} / \mathrm{min}$ & $0.37 \pm 0.02 \mathrm{~mL} / \mathrm{min}$ \\
$\mathrm{IL}-17 \mathrm{~A}(\mathrm{pg} / \mathrm{mL})$ & $27.3 \pm 5.3 \mathrm{pg} / \mathrm{mL}^{\dagger}$ & $13.4 \pm 1.2 \mathrm{pg} / \mathrm{mL}^{\S}$ & $5.2 \pm 1.3 \mathrm{pg} / \mathrm{mL}^{\mathbb{T}}$ & $0.4 \pm 0.008 \mathrm{pg} / \mathrm{mL}$ \\
$\mathrm{IL}-23(\mathrm{pg} / \mathrm{mL})$ & $239.4 \pm 8.1 \mathrm{pg} / \mathrm{mL}^{\ddagger}$ & $125.2 \pm 8.6 \mathrm{pg} / \mathrm{mL}$ & $66.1 \pm 7.4 \mathrm{pg} / \mathrm{mL}$ & $30.4 \pm 0.05 \mathrm{pg} / \mathrm{mL}$ \\
\hline
\end{tabular}

IL: Interleukin. SFR: Salivary flow rate. ${ }^{*}$ Compared with cigarette-smokers $(p<0.01)$ and non-smokers with periodontitis $(p<0.01) ;{ }^{\dagger}$ Compared with cigarette-smokers $(p<0.01)$ and non-smokers with periodontitis $(p<0.01)$; $\ddagger$ Compared with cigarette-smokers $(p<0.01)$ and non-smokers with periodontitis $(p<0.01)$; ${ }^{\circledR}$ Compared with non-smokers with periodontitis $(p<0.01)$; " Compared with non-smokers with periodontitis $(p<0.01)$ and periodontally-healthy individuals $(p<0.01)$; II Compared with periodontally-healthy individuals $(p<0.01)$;

\# Compared with periodontally-healthy individuals $(p<0.01)$.

\section{Discussion}

From a clinicoradiographic perspective, the present results showed that periodontal inflammatory status was worse in marijuana-smokers and cigarette-smokers compared with non-smokers without periodontitis (positive controls). These results are in accordance with previous clinical studies $[9,13]$. One justification for this is that nicotine (a major and addictive component in tobacco) induces destructive effects on human gingival fibroblasts (HGF), periodontal ligament cells and alveolar bone [40,41]. Moreover, results from an in-vitro study [42] showed that exposure of HGF to high concentrations of nicotine and cotinine (a metabolite of nicotine) impairs their attachment to root surfaces. With reference to detrimental effects of marijuana-smoking on alveolar bone, results from an experimental study in rat-models showed that marijuana-smoke inhalation increases alveolar bone loss and decreases bone density [43]. According to Nakajima et al. [44] cannabinoids possibly contribute towards the etiopathogenesis of periodontitis via expression of cannabinoid receptors in periodontal tissues. The present results no significant difference in clinical and radiographic periodontal inflammatory parameters among heavy cigarette-smokers and marijuana-smokers. This was in contradiction to the proposed hypothesis. It is noteworthy that in the present study, marijuana was smoked as a "spliff," which is a combination of marijuana and tobacco wrapped in a thin paper. The authors speculate that both marijuana and nicotine induce comparable levels of periodontal destruction; and hence nicotine exposure during heavy cigarette-smoking induces clinicoradiographic periodontal inflammatory effects that are similar to using marijuana as a "spliff." However, this is merely a speculation and further studies are warranted to confirm this hypothesis. Despite the clinicoradiographic similarities among cigarette- and marijuana-smokers, a marked variation in the expression of proinflammatory cytokines in the UWS was noted in these individuals. The present results showed that whole salivary IL-17A and IL-23 levels were significantly higher in the UWS of marijuana-smokers compared with non-smokers with periodontitis. This suggests that whole salivary assessment of IL-17A and IL-23 can be used as a biomarker of periodontitis especially among tobacco-smokers and recreational-drug smokers. Our results further demonstrate that on a molecular level, the deleterious effects of smoking marijuana as a "spliff" are worse than smoking cigarettes. However, by no means does this imply that cigarette-smoking is safer than smoking Cannabis. The authors performed a regression analysis to corelate the clinicoradiographic parameters and whole salivary IL-17 and IL-23 levels with age, gender education status and frequency of smoking cigarettes 
and marijuana; however, no statistically significant association between these parameters existed (data not shown).

In the present study, exclusively heavy cigarette-smokers were included. A reasoning for this criterion was based on the perception that since marijuana jeopardizes HGF, periodontal ligament cells as well as alveolar bone $[40,41]$; comparison of marijuana-smokers with light- and moderate cigarette-smokers may give false-positive outcomes. However, there is a lack of consensus regarding the precise classification of cigarette-smokers based upon smoking history (pack-years). For instance, in the study by Hassan et al. [45] heavy-smokers were defined as individuals who reported over 20 pack-years of smoking; whereas in the studies by Langevin et al. [46] and Karlsson et al. [47] heavy-smokers were defined as individuals who had a smoking history of more than 18.3 and 60 pack-years, respectively. In the present study, individuals with a cigarette-smoking history of at least 40 pack-years were classified as "heavy" cigarette-smokers as this criterion seems to be a rather median value for the wide range pack-year based ( 18 to $\sim 60$ pack-years) definitions used to define "heavy-smokers." The definition of heavy-smokers used in the present observational study is in consistence with the study by Costa et al. [23]; however, there is a dire need to implicate and adopt standardized criteria for definition of "light", "moderate" 78 and "heavy" cigarette smokers that can be implicated globally for clinical and biomedical research purposes. It is further suggested that criteria for classification for recreational-drug (such a marijuana-smokers) users based upon recreational-drug use history may also be useful for future studies in the related field.

Determination of the optimal sample-size for a study is critical as it helps estimate the power to detect statistical significances [48]. In this regard, a major limitation of the present study is that a prior sample-size estimation (power analysis was not performed. Therefore, the reported $p$-value for group-comparisons should be cautiously interpreted. Moreover, education status was poorer among marijuana- and heavy cigarette-smokers compared with non-smokers with periodontitis and periodontally-healthy controls. Interdental flossing and routine visits to oral healthcare providers were more often reported by periodontally-healthy individuals compared with patients in other groups. These factors could have contributed towards worsening periodontal inflammation among marijuana-smokers, heavy cigarette-smokers and non-smokers with periodontitis. It is also noteworthy that tobacco-smoking was self-reported in the present study. However, a true determination of a person being a smoker or a passive/non-smoker can be done using biological investigations such as assessment of whole salivary cotinine levels [11]. Furthermore, based upon the staging and grading criteria, periodontal inflammation was worse in marijuana-and cigarette smokers compared with non-smokers with periodontitis. It is speculated that non-smokers with a staging and grading of periodontitis may demonstrate IL-17 and IL-23 levels that are comparable with cigarette-smokers and marijuana-smokers. At least $73 \%$ of the heavy-cigarette-smokers and all (100\%) marijuana-smokers reported that they achieved a state of mind referred to as "stress relief" after using their respective products. It is possible that these individuals had an underprivileged socioeconomic status that could be associated with their poor education status. This could have compelled these individuals to use tobacco (cigarettes as in the present scenario) and cannabis to temporarily alleviate socioeconomic-based stresses. Patient health education and anti-tobacco and cannabis based programs may play a role in improving the quality of life of susceptible populations. Further studies are needed to test these hypotheses.

\section{Conclusions}

Marijuana- and heavy cigarette-smokers have comparable clinicoradiographic periodontal statuses. This rejects hypothesis-1. However, whole salivary immunoinflammatory response may be moderately worse in marijuana-smokers compared with heavy cigarette-smokers and non-smoker with periodontitis thereby supporting hypothesis- 2 . 
Author Contributions: All authors have made substantial contribution to the conception and design of the present study. A.M. was involved in data collection and D.D.D., A.A., A.A.A.-K. and K.S.A. were involved in data entry. K.S.A., D.D.D., F.J. and A.A.A.-K. have been involved in data interpretation. F.J., A.S.A.-Z., K.S.A., D.D.D. and A.A.A.-K. drafted the manuscript and revised it critically prior to submission. All authors have given final approval of the version to be published. All authors have read and agreed to the published version of the manuscript.

Funding: This research received no external funding.

Acknowledgments: The authors are grateful to the Deanship of Scientific Research, King Saud University, Riyadh, Saudi Arabia for funding through Vice Deanship of Scientific Research Chairs.

Conflicts of Interest: The authors declare that they have no conflict of interest related to the present study.

\section{References}

1. Berg, C.J.; Henriksen, L.; Cavazos-Rehg, P.; Schauer, G.L.; Freisthler, B. The development and pilot testing of the marijuana retail surveillance tool (MRST): Assessing marketing and point-of-sale practices among recreational marijuana retailers. Health Educ. Res. 2017, 32, 465-472. [CrossRef] [PubMed]

2. Carliner, H.; Mauro, P.M.; Brown, Q.L.; Shmulewitz, D.; Rahim-Juwel, R.; Sarvet, A.L.; Wall, M.M.; Martins, S.S.; Carliner, G.; Hasin, D.S. The widening gender gap in marijuana use prevalence in the U.S. during a period of economic change, 2002-2014. Drug Alcohol Depend. 2017, 170, 51-58. [CrossRef] [PubMed]

3. Russo, E.B. Taming THC: Potential cannabis synergy and phytocannabinoid-terpenoid entourage effects. Br. J. Pharmacol. 2011, 163, 1344-1364. [CrossRef] [PubMed]

4. Lee, C.M.; Neighbors, C.; Woods, B.A. Marijuana motives: Young adults' reasons for using marijuana. Addict. Behav. 2007, 32, 1384-1394. [CrossRef]

5. Nagarkatti, P.; Pandey, R.; Rieder, S.A.; Hegde, V.L.; Nagarkatti, M. Cannabinoids as novel anti-inflammatory drugs. Future Med. Chem. 2009, 1, 1333-1349. [CrossRef]

6. Chen, J.; Hou, C.; Chen, X.; Wang, D.; Yang, P.; He, X.; Zhou, J.; Li, H. Protective effect of cannabidiol on hydrogen peroxide-induced apoptosis, inflammation and oxidative stress in nucleus pulposus cells. Mol. Med. Rep. 2016, 14, 2321-2327. [CrossRef]

7. Hasin, D.S.; Saha, T.D.; Kerridge, B.T.; Goldstein, R.B.; Chou, S.P.; Zhang, H.; Jung, J.; Pickering, R.P.; Ruan, W.J.; Smith, S.M.; et al. Prevalence of Marijuana Use Disorders in the United States Between 2001-2002 and 2012-2013. JAMA Psychiatry 2015, 72, 1235-1242. [CrossRef]

8. Wilkinson, S.T.; Yarnell, S.; Radhakrishnan, R.; Ball, S.A.; D'Souza, D.C. Marijuana Legalization: Impact on Physicians and Public Health. Annu. Rev. Med. 2016, 67, 453-466. [CrossRef]

9. Shariff, J.A.; Ahluwalia, K.P.; Papapanou, P.N. Relationship Between Frequent Recreational Cannabis (Marijuana and Hashish) Use and Periodontitis in Adults in the United States: National Health and Nutrition Examination Survey 2011 to 2012. J. Periodontol. 2017, 88, 273-280. [CrossRef]

10. Chisini, L.A.; Cademartori, M.G.; Francia, A.; Mederos, M.; Grazioli, G.; Conde, M.C.M.; Correa, M.B. Is the use of Cannabis associated with periodontitis? A systematic review and meta-analysis. J. Periodontal Res. 2019, 54, 311-317. [CrossRef]

11. Mokeem, S.A.; Alasqah, M.N.; Michelogiannakis, D.; Al-Kheraif, A.A.; Romanos, G.E.; Javed, F. Clinical and radiographic periodontal status and whole salivary cotinine, IL- $1 \beta$ and IL-6 levels in cigarette- and waterpipe-smokers and E-cig users. Environ. Toxicol. Pharmacol. 2018, 61, 38-43. [CrossRef]

12. Rodríguez-Rabassa, M.; López, P.; Rodríguez-Santiago, R.E.; Cases, A.; Felici, M.; Sánchez, R.; Yamamura, Y.; Rivera-Amill, V. Cigarette Smoking Modulation of Saliva Microbial Composition and Cytokine Levels. Int. J. Environ. Res. Public Health 2018, 15, 2479. [CrossRef]

13. Javed, F.; Näsström, K.; Benchimol, D.; Altamash, M.; Klinge, B.; Engström, P.E. Comparison of periodontal and socioeconomic status between subjects with type 2 diabetes mellitus and non-diabetic controls. J. Periodontol. 2007, 78, 2112-2119. [CrossRef]

14. Korn, T.; Bettelli, E.; Oukka, M.; Kuchroo, V.K. IL-17 and Th17 Cells. Annu. Rev. Immunol. 2009, $27,485-517$. [CrossRef] [PubMed]

15. Liukkonen, J.; Gürsoy, U.K.; Pussinen, P.J.; Suominen, A.L.; Könönen, E. Salivary Concentrations of Interleukin (IL)-1 $\beta$, IL-17A, and IL-23 Vary in Relation to Periodontal Status. J. Periodontol. 2016, 87, 1484-1491. [CrossRef] [PubMed] 
16. Beklen, A.; Ainola, M.; Hukkanen, M.; Gürgan, C.; Sorsa, T.; Konttinen, Y.T. MMPs, IL-1, and TNF are regulated by IL-17 in periodontitis. J. Dent. Res. 2007, 86, 347-351. [CrossRef] [PubMed]

17. Kramer, J.M.; Gaffen, S.L. Interleukin-17: A new paradigm in inflammation, autoimmunity, and therapy. J. Periodontol. 2007, 78, 1083-1093. [CrossRef]

18. McKenzie, B.S.; Kastelein, R.A.; Cua, D.J. Understanding the IL-23-IL-17 immune pathway. Trends Immunol. 2006, 27, 17-23. [CrossRef] [PubMed]

19. Bunte, K.; Beikler, T. Th17 Cells and the IL-23/IL-17 Axis in the Pathogenesis of Periodontitis and Immune-Mediated Inflammatory Diseases. Int. J. Mol. Sci. 2019, 20, 3394. [CrossRef] [PubMed]

20. Luo, Z.; Wang, H.; Wu, Y.; Sun, Z.; Wu, Y. Clinical significance of IL-23 regulating IL-17A and/or IL-17F positive Th17 cells in chronic periodontitis. Mediat. Inflamm. 2014, 2014, 627959. [CrossRef]

21. Ohyama, H.; Kato-Kogoe, N.; Kuhara, A.; Nishimura, F.; Nakasho, K.; Yamanegi, K.; Yamada, N.; Hata, M.; Yamane, J.; Terada, N. The involvement of IL-23 and the Th17 pathway in periodontitis. J. Dent. Res. 2009, 88, 633-638. [CrossRef] [PubMed]

22. Mohanty, P.; Gujjari, S.K.; Nakum, C.G. Salivary free hemoglobin and lactate dehydrogenase as biomarkers for periodontal disease in smokers. Quintessence Int. 2019, 50, 428-434. [PubMed]

23. Costa, F.O.; Cota, L.O.; Lages, E.J.; Cyrino, R.M.; Oliveira, A.M.; Oliveira, P.A.; Cortelli, J.R. Associations of duration of smoking cessation and cumulative smoking exposure with periodontitis. J. Oral Sci. 2013, 55, 245-253. [CrossRef] [PubMed]

24. Lee, Y.H.; Shin, M.H.; Kweon, S.S.; Choi, J.S.; Rhee, J.A.; Ahn, H.R.; Yun, W.J.; Ryu, S.Y.; Kim, B.H.; Nam, H.S.; et al. Cumulative smoking exposure, duration of smoking cessation, and peripheral arterial disease in middle-aged and older Korean men. BMC Public Health 2011, 11, 94. [CrossRef]

25. Lorenz, D.R.; Uno, H.; Wolinsky, S.M.; Gabuzda, D. Effect of marijuana smoking on pulmonary disease in HIV-infected and uninfected men: A longitudinal cohort study. EClinicalMedicine 2019, 7, 55-64. [CrossRef]

26. Mehmood, A.; Abduljabbar, T.; Al-Hamoudi, N.; Gholamiazizi, E.; Kellesarian, S.V.; Vohra, F.; Javed, F. Self-perceived oral symptoms and periodontal status among young intravenous heroin addicts: A cross-sectional case-control study. J. Periodontol. 2018, 89, 571-576. [CrossRef]

27. Mahmood, N.; Zahid, G.M. Measuring the education gap in primary and secondary schooling in Pakistan. Pak. Dev. Rev. 1992, 31, 729-738. [CrossRef]

28. Khan, M.J.; Fatima, S.; Akhtar, M.; Owais, M. Why should the faculty adopt reciprocal teaching as part of the medical curriculum? J. Ayub. Med. Coll. Abbottabad. 2016, 28, 832-835.

29. Buzdar, M.A.; Ali, A.; Nadeem, M.; Nadeem, M. Relationship between Religiosity and Psychological Symptoms in Female University Students. J. Relig. Health 2015, 54, 2155-2163. [CrossRef]

30. Armitage, G.C.; Dickinson, W.R.; Jenderseck, R.S.; Levine, S.M.; Chambers, D.W. Relationship between the percentage of subgingival spirochetes and the severity of periodontal disease. J. Periodontol. 1982, 53, 550-556. [CrossRef]

31. Loe, H. The Gingival Index, the Plaque Index and the Retention Index Systems. J. Periodontol. 1967, 38, 610-616. [CrossRef]

32. Armitage, G.C.; Svanberg, G.K.; Loe, H. Microscopic evaluation of clinical measurements of connective tissue attachment levels. J. Clin. Periodontol. 1977, 4, 173-190. [CrossRef] [PubMed]

33. Updegrave, W.J. The paralleling extension-cone technique in intraoral dental radiography. Oral Surg. Oral Med. Oral Pathol. 1951, 4, 1250-1261. [CrossRef]

34. Khocht, A.; Janal, M.; Harasty, L.; Chang, K.M. Comparison of direct digital and conventional intraoral radiographs in detecting alveolar bone loss. J. Am. Dent. Assoc. 2003, 134, 1468-1475. [CrossRef]

35. Qadri, T.; Javed, F.; Johannsen, G.; Gustafsson, A. Role of diode lasers (800-980 nm) as adjuncts to scaling and root planing in the treatment of chronic periodontitis: A systematic review. Photomed. Laser Surg. 2015, 33, 568-575. [CrossRef]

36. Chapple, I.L.C.; Mealey, B.L.; Van Dyke, T.E.; Bartold, P.M.; Dommisch, H.; Eickholz, P.; Geisinger, M.L.; Genco, R.J.; Glogauer, M.; Goldstein, M.; et al. Periodontal health and gingival diseases and conditions on an intact and a reduced periodontium: Consensus report of workgroup 1 of the 2017 World Workshop on the Classification of Periodontal and Peri-Implant Diseases and Conditions. J. Periodontol. 2018, 89 (Suppl. 1), S74-S84. [CrossRef] 
37. Papapanou, P.N.; Sanz, M.; Buduneli, N.; Dietrich, T.; Feres, M.; Fine, D.H.; Flemmig, T.F.; Garcia, R.; Giannobile, W.V.; Graziani, F.; et al. Periodontitis: Consensus report of workgroup 2 of the 2017 World Workshop on the Classification of Periodontal and Peri-Implant Diseases and Conditions. J. Periodontol. 2018, 89 (Suppl. 1), S173-S182. [CrossRef]

38. Javed, F.; Ahmed, H.B.; Saeed, A.; Mehmood, A.; Bain, C. Whole salivary interleukin-6 and matrix metalloproteinase- 8 levels in patients with chronic periodontitis with and without prediabetes. J. Periodontol. 2014, 85, e130-e135. [CrossRef]

39. Javed, F.; Al-Kheraif, A.A.; Al Amri, M.D.; Mikami, T.; Vohra, F.; Warnakulasuriya, S.; Romanos, G.E. Periodontal parameters and whole salivary cytokine profiles among habitual gutka chewers and non-chewers. J. Periodontol. 2015, 86, 689-695. [CrossRef]

40. Javed, F.; Kellesarian, S.V.; Sundar, I.K.; Romanos, G.E.; Rahman, I. Recent updates on electronic cigarette aerosol and inhaled nicotine effects on periodontal and pulmonary tissues. Oral Dis. 2017, 23, 1052-1057. [CrossRef]

41. Bosco, A.F.; Bonfante, S.; de Almeida, J.M.; Luize, D.S.; Nagata, M.J.; Garcia, V.G. A histologic and histometric assessment of the influence of nicotine on alveolar bone loss in rats. J. Periodontol. 2007, 78, 527-532. [CrossRef]

42. Esfahrood, Z.R.; Zamanian, A.; Torshabi, M.; Abrishami, M. The effect of nicotine and cotinine on human gingival fibroblasts attachment to root surfaces. J. Basic Clin. Physiol. Pharmacol. 2015, 26, 517-522. [CrossRef] [PubMed]

43. Nogueira-Filho, G.R.; Todescan, S.; Shah, A.; Rosa, B.T.; Tunes Uda, R.; Cesar Neto, J.B. Impact of cannabis sativa (marijuana) smoke on alveolar bone loss: A histometric study in rats. J. Periodontol. 2011, 82, 1602-1607. [CrossRef] [PubMed]

44. Nakajima, Y.; Furuichi, Y.; Biswas, K.K.; Hashiguchi, T.; Kawahara, K.; Yamaji, K.; Uchimura, T.; Izumi, Y.; Maruyama, I. Endocannabinoid, anandamide in gingival tissue regulates the periodontal inflammation through NF-kappaB pathway inhibition. FEBS Lett. 2006, 580, 613-619. [CrossRef] [PubMed]

45. Hassan, M.M.; Spitz, M.R.; Thomas, M.B.; El-Deeb, A.S.; Glover, K.Y.; Nguyen, N.T.; Chan, W.; Kaseb, A.; Curley, S.A.; Vauthey, J.N.; et al. Effect of different types of smoking and synergism with hepatitis $C$ virus on risk of hepatocellular carcinoma in American men and women: Case-control study. Int. J. Cancer 2008, 123, 1883-1891. [CrossRef] [PubMed]

46. Langevin, S.M.; Michaud, D.S.; Marsit, C.J.; Nelson, H.H.; Birnbaum, A.E.; Eliot, M.; Christensen, B.C.; McClean, M.D.; Kelsey, K.T. Gastric reflux is an independent risk factor for laryngopharyngeal carcinoma. Cancer Epidemiol. Biomark. Prev. 2013, 22, 1061-1068. [CrossRef] [PubMed]

47. Karlsson, A.; Ringnér, M.; Lauss, M.; Botling, J.; Micke, P.; Planck, M.; Staaf, J. Genomic and transcriptional alterations in lung adenocarcinoma in relation to smoking history. Clin. Cancer Res. 2014, 20, 4912-4924. [CrossRef]

48. Noordzij, M.; Tripepi, G.; Dekker, F.W.; Zoccali, C.; Tanck, M.W.; Jager, K.J. Sample size calculations: Basic principles and common pitfalls. Nephrol. Dial. Transplant. 2010, 25, 1388-1393. [CrossRef]

(C) 2020 by the authors. Licensee MDPI, Basel, Switzerland. This article is an open access article distributed under the terms and conditions of the Creative Commons Attribution (CC BY) license (http://creativecommons.org/licenses/by/4.0/). 